Research Paper

\title{
HOXC6 Overexpression Is Associated With Ki-67 Expression and Poor Survival in NPC Patients
}

\author{
Shih-Lun Chang1, 2, Ti-Chun Chan³ ${ }^{3}$ Tzu-Ju Chen², 4, Sung-Wei Lee ${ }^{5}$, Li-Ching Lin ${ }^{6}$, Khin Than Win ${ }^{4}$ \\ 1. Department of Otolaryngology, Chi Mei Medical Center, Yongkang District, Tainan City, Taiwan; \\ 2. Department of Optometry, Chung Hwa University of Medical Technology, Tainan, Taiwan; \\ 3. Department of Medical Research, Chi Mei Medical Center, Tainan, Taiwan; \\ 4. Department of Pathology, Chi Mei Medical Center, Tainan, Taiwan; \\ 5. Department of Radiation Oncology, Chi Mei Medical Center, Liouying, Tainan, Taiwan; \\ 6. Department of Radiation Oncology, Chi Mei Medical Center, Tainan, Taiwan. \\ $\square$ Corresponding author: Khin Than Win, M.D., Department of Pathology, Chi Mei Medical Center, Tainan 710, Taiwan. E-mail: a10905@mail.chimei.org.tw \\ (c) Ivyspring International Publisher. This is an open access article distributed under the terms of the Creative Commons Attribution (CC BY-NC) license \\ (https://creativecommons.org/licenses/by-nc/4.0/). See http://ivyspring.com/terms for full terms and conditions.
}

Received: 2016.12.23; Accepted: 2017.03.26; Published: 2017.06.03

\begin{abstract}
BACKGROUND: Homeobox $(H O X)$ genes are expressed in adult cells and regulate expression of genes involved in cell proliferation as well as cell-cell and cell-extracellular matrix interactions. Dysregulation of HOX gene expression plays important roles in carcinogenesis in a variety of organs. Through data mining on a published transcriptome dataset, this study first identified Homeobox protein Hox-C6 (HOXC6) gene as one of the differentially upregulated genes in nasopharyngeal carcinoma (NPC). We aimed to evaluate HOXC6 expression and its prognostic effect in a large cohort of NPC patients.

METHODS: We retrospectively examined the HOXC6 expression and $\mathrm{Ki}-67$ index by immunohistochemistry in biopsy specimens from 124 patients with non-metastasized NPC. The results were correlated with the clinicopathological variables including disease-specific survival (DSS), metastasis-free survival (MeFS), and local recurrence-free survival (LRFS).

RESULTS: HOXC6 high expression was positively correlated with increased Ki-67 labeling index, and significantly associated with increment of tumor stage $(p=0.024)$, advanced nodal status $(p<0.001)$ and American Joint Committee on Cancer $(A J C C)$ stage $(p=0.002)$. Its expression also correlated with worse prognosis in terms of DSS $(p=0.008)$, MeFS $(p=0.0047)$ univariately. In multivariate analyses, HOXC6 expression still remained prognostically independent to portend worse DSS $(p=0.015$, hazard ratio $=1.988)$ and MeFS $(p=0.036$, hazard ratio=1.899), together with stage III-IV $(p=0.024$, DSS; $p=0.043$, MeFS).
\end{abstract}

CONCLUSION: In summary, our results suggest HOXC6 may play a critical role in NPC progression and may serve as a potential prognostic biomarker in NPC patients.

Key words: HOXC6, nasopharyngeal carcinoma, Prognosis.

\section{Introduction}

Nasopharyngeal carcinoma (NPC) is one of the most lethal malignancies with the highest prevalence in southern China and south-east Asia, and is closely associated with Epstein-Barr virus (EBV) infection [1]. In Taiwan, the incidence of NPC is eight to ten cases per 100,000 person/years (database from Bureau of Health Promotion, Taiwan). Most NPC are histologically poorly differentiated or undifferentiated, with a great tendency towards regional invasion and lymph node metastases. Despite a high loco-regional control rate with modern radiotherapy, distant metastasis remains a major threat to NPC patients, highlighting the complex nature of NPC tumorigenesis and importance of effective systemic therapy [2]. Although conventional TNM staging information has a strong prognostic significance in NPC, there are limited predictive biomarkers of chemo-radiotherapy responses for this cancer. To identify critical genes associated with tumorigenesis in NPC, we analyzed gene expression in a published transcriptomic dataset and identified the HOXC6 gene as one of the differentially upregulated genes associated with the regulation of transcription from the RNA polymerase II promoter 
in the transcriptome of NPCs. We explored the significance of the HOXC6 expression status using immunohistochemistry and characterized the association of this gene with cell proliferation via Ki-67 labeling in a large cohort of NPC patients.

In the last decade, a great deal has been learned about the molecular genetic regulation of mammalian embryonic development. Mammalian homeobox genes that share a homeodomain highly related to the homeodomain of the Drosophila Antennapedial Bithorax complex genes have been identified [3]. Mouse and human genes belonging to this class are termed HOX genes [4, 5]. In humans, four distinct clusters (HOXA, HOXB, HOXC, and HOXD) have been identified on four distinct chromosomes (chromosome 7, 17, 12, and 2, respectively) [6]. These clusters contain transcription factors involved in controlling and coordinating complex functions during development via spatial and temporal expression patterns. HOXC6 is one of several HOXC genes located in a cluster on chromosome 12.

Increasing evidence has shown that the dysregulation of HOX gene expression plays important roles in carcinogenesis [7, 8], although the precise mechanisms are incompletely understood. In some cases, these genes may function as transcription factors that stimulate the expression of growth factors, such as the HoxB7-mediated up-regulation of fibroblast growth factor in melanomas [9]. The overexpression of HOXC6 has been observed in human prostate cancer, where it inhibits apoptosis $[10,11]$.

Despite many reports of aberrant homeobox gene expression in solid tumors, our current knowledge is far from complete. Currently, the expression status and clinical relevance of the HOX genes in NPC have not yet been investigated. Assuming that the oncogenic activities of homeoproteins being attributed to inappropriate effects on cell-cycle regulation, we intended to perform a comprehensive survey of HOXC6 expression in association with cellular proliferation and its correlations with clinicopathological parameters in NPC specimens. Ki-67 is an established cellular marker for proliferation, expressed in all cycling cells, except resting cells in G0 phase. Its cellular function, however, remains elusive. It has been suggested that $\mathrm{Ki}-67$ functions primarily in mitosis, and may also be involved in DNA synthesis [12]. Hence, we chose Ki-67 as one of the pathological parameters and checked its correlation with HOXC6 expression.

\section{Materials and Methods}

\section{Data mining of the GEO database}

To identify critical genes in the pathogenesis of NPC, we reappraised the transcriptome dataset deposited in Gene Expression Omnibus (GDS3610) of NPC tissues $(n=25)$ versus non-neoplastic nasopharyngeal mucosal epithelial tissues $(n=3)$ enriched by laser capture microdissection of the cells of interest (Fig. 1). We analyzed the gene expression levels by importing the raw CEL files of the Affymetrix HUMAN Genome U133 Plus 2.0 microarray platform into Nexus Expression 3 software (BioDiscovery) as previously described [12-14]. All probe sets were tested without pre-selection or filtering. Supervised comparative analysis and functional profiling were performed to identify significant differentially expressed genes associated with the regulation of transcription from the RNA polymerase II promoter in the transcriptome of NPCs. Those with $p<0.01$ and log2-transformed expression fold-change $>1$ were selected for further analysis. Among the statistically significant genes, HOXC6 appeared as the top ranking differentially expressed candidate (Table 1), prompting us to further characterize the immunoexpression level of HOXC6 in the NPC cohort.

Table 1. Summary of differentially expressed genes associated with regulation of transcription from RNA polymerase II promoter in the transcriptome of nasopharyngeal carcinomas

\begin{tabular}{|c|c|c|c|c|c|c|}
\hline Probe & $\begin{array}{l}\text { Comparison } 1 \text { Log } \\
\text { ratio (NPC vs. } \\
\text { Non-tumor tissue) }\end{array}$ & $\begin{array}{l}\text { Comparison } \\
\text { p-value }\end{array}$ & $\begin{array}{l}\text { Gene } \\
\text { Symbol }\end{array}$ & Gene Name & Biological Process & Molecular Function \\
\hline 206858_s_at & 3.0467 & $<0.0001$ & HOXC6 & homeobox C6 & $\begin{array}{l}\text { multicellular organismal development, } \\
\text { regulation of transcription, regulation of } \\
\text { transcription from RNA polymerase II promoter, } \\
\text { regulation of transcription; DNA-dependent, } \\
\text { transcription }\end{array}$ & $\begin{array}{l}\text { DNA binding, sequence-specific } \\
\text { DNA binding, transcription } \\
\text { corepressor activity, transcription } \\
\text { factor activity }\end{array}$ \\
\hline 229551_x_at & 1.9493 & $<0.0001$ & ZNF367 & $\begin{array}{l}\text { zinc finger } \\
\text { protein } 367\end{array}$ & $\begin{array}{l}\text { regulation of transcription from RNA } \\
\text { polymerase II promoter, regulation of } \\
\text { transcription; DNA-dependent, transcription }\end{array}$ & $\begin{array}{l}\text { DNA binding, metal ion binding, } \\
\text { nucleic acid binding, transcription } \\
\text { factor activity, zinc ion binding }\end{array}$ \\
\hline 225655_at & 1.7408 & $<0.0001$ & UHRF1 & $\begin{array}{l}\text { ubiquitin-like; } \\
\text { containing } \\
\text { PHD and } \\
\text { RING finger } \\
\text { domains; } 1\end{array}$ & $\begin{array}{l}\text { DNA repair, cell cycle, cell proliferation, protein } \\
\text { modification process, regulation of transcription } \\
\text { from RNA polymerase II promoter, regulation of } \\
\text { transcription; DNA-dependent, response to DNA } \\
\text { damage stimulus, transcription, ubiquitin cycle }\end{array}$ & $\begin{array}{l}\text { DNA binding, RNA polymerase II } \\
\text { transcription factor activity, ligase } \\
\text { activity, metal ion binding, protein } \\
\text { binding, transcription factor } \\
\text { activity, zinc ion binding }\end{array}$ \\
\hline
\end{tabular}



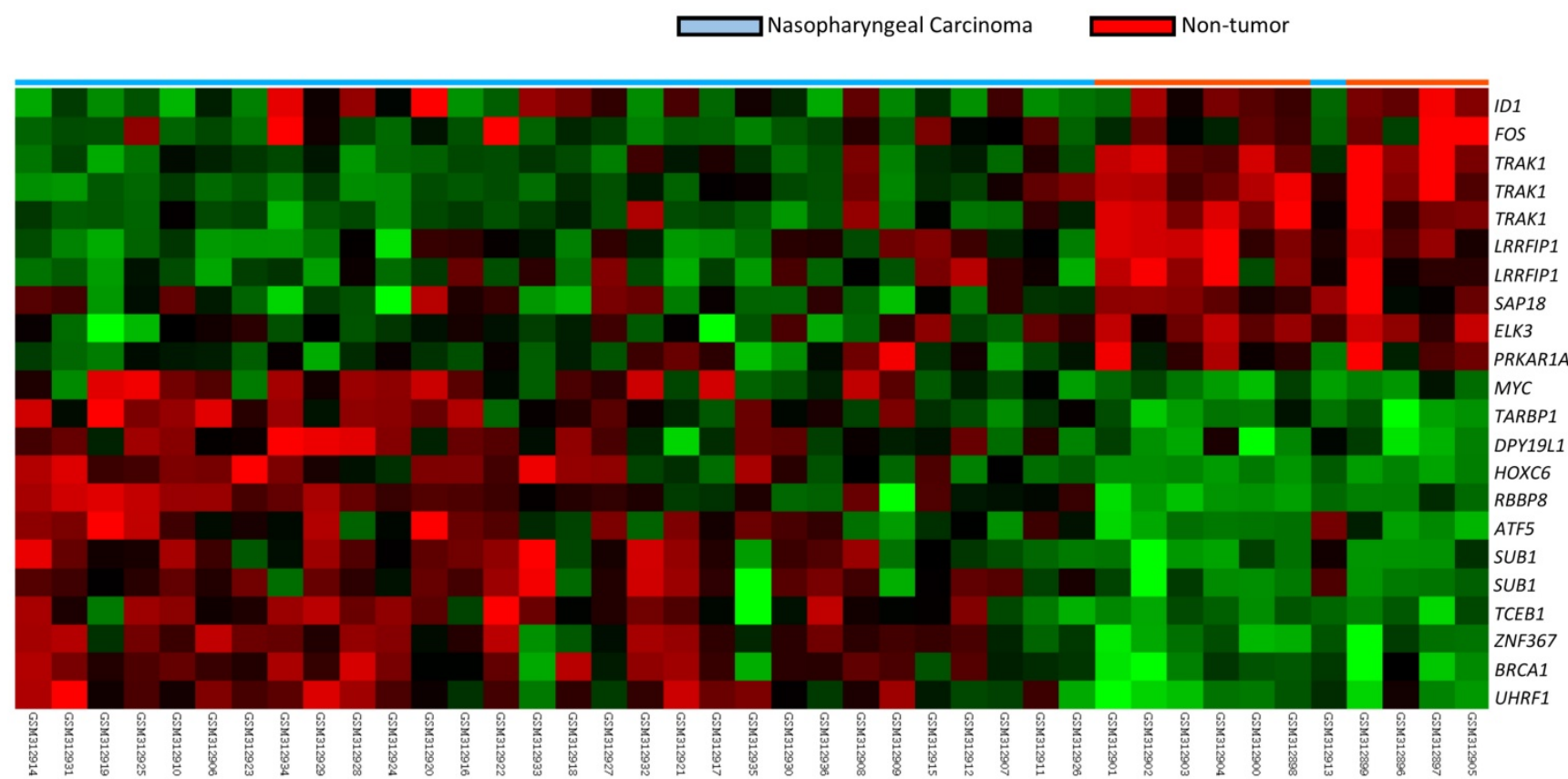

Figure 1. A heat map demonstrating data mining on GDS3610 (GEO database). Specimen identity of non-tumor ( $\mathrm{n}=10$ ) and tumor ( $\mathrm{n}=31$ ) are shown. Low expression values are green, progression to dark and reds for higher values.

\section{Patients and tumor specimens}

The use of formalin-fixed NPC tissues was approved by the institutional review board (IRB10302013). Available paraffin-embedded tissue blocks were retrieved from 124 consecutive NPC patients who underwent biopsies between January 1993 and December 2002 as previously reported [13-15]. All patients were free of distant metastases during initial diagnosis. The histological subtypes were reappraised according to the current WHO classification and, the tumor staging was documented according to the 7th American Joint Committee on Cancer (AJCC) system by two pathologists (TJC and KTW), independently.

\section{Immunohistochemical staining of $\mathrm{HOXC6}$ and Ki-67}

The protocol for immunostaining was based on our previous works [18-20]. In short, tissue sections were cut from paraffin-embedded blocks at $3-\mu \mathrm{m}$ thickness and placed onto pre-coated slides. The slides were subsequently deparaffinized with xylene and rehydrated with ethanol washes using routine methods. Antigen retrieval was performed with 10 $\mathrm{mM}$ citrate buffer ( $\mathrm{pH}$ 6.0) by heating in a microwave at a controlled final temperature of $121{ }^{\circ} \mathrm{C}$ for 10 min. After blocking endogenous peroxidase with 3\% $\mathrm{H}_{2} \mathrm{O}_{2}$, the slides were washed with Tris-buffered saline for $15 \mathrm{~min}$ and incubated with a primary antibody targeting HOXC6 (dilution 1:200, ab41587, Abcam, Cambridge, UK) or Ki-67 antigen (dilution
1:200, clone MIB-1, sc-101861, Santa Cruz) for 1 hour, respectively. Primary antibodies were detected using the ChemMate DAKO EnVision kit (DAKO, K5001, Carpinteria, CA). The slides were subsequently incubated with the secondary antibody for $30 \mathrm{~min}$ at room temperature, developed with 3,3-diaminobenzidine for $5 \mathrm{~min}$, and counterstained with hematoxylin, followed by dehydration and mounting. Rabbit serum IgG was used as a negative control.

\section{Immunohistochemical data analysis and scoring of $\mathrm{HOXC6}$ and $\mathrm{Ki}-67$}

Two pathologists (TJC and KTW) scored the HOXC6 expression and the Ki-67 labeling index using a multi-headed microscope, reaching consensus for each case without knowing the associated clinicopathological parameters and clinical outcomes of the patients. The immunoreactivity of HOXC6 and $\mathrm{Ki}-67$ was assessed based on the histological score $(\mathrm{H}$ score) as previously described [18-20]. Briefly, this score was calculated using the following equation: $\mathrm{H}$ score $=\Sigma \mathrm{Pi}(\mathrm{i}+1)$, where $\mathrm{i}$ stands for the intensity (ranging from 0 to 4 ), and $\mathrm{Pi}$ is the percentage of the stained tumor cells of intensity varying from 0 to $100 \%$. Cases with an $\mathrm{H}$ score larger than the median value were determined to have high expression.

\section{Treatment and follow-up}

All 124 cases received complete courses of radiotherapy with daily fractionation of 180-200 cGy and five fractions weekly (total dose $\geq 7000 \mathrm{cGy}$ ). The 
patients with stage II-IV diseases also received cisplatin-based chemotherapy in addition to a complete course of radiotherapy according to the previously published protocol [16]. Seven patients treated in the earlier phase of the cohort were not available for instantaneous image studies after therapy as a baseline for evaluating treatment response. There were 110 complete responders and seven partial responders according to a previously reported methodology adapted from WHO criteria using clinical examinations and imaging modalities to assess treatment responses. The radiotherapy protocol was generally constant over this period. All 124 patients were regularly monitored after radiotherapy until death or their last visit to our hospital, with a mean follow-up duration of 67 months (median 71; range 1-141) for the total cohort and 94 months (median 95; range 10-141) for those without further events.

\section{Statistical analysis}

The SPSS V.14 software package was used to perform statistical data analyses. The Chi-square test was applied to analyze the relationship between HOXC6 immuno-expression and various clinicopathological parameters. The endpoints analyzed were local recurrence-free survival (LRFS), distant metastasis-free survival (DMFS), and disease-specific survival (DSS) were calculated from the starting date of radiotherapy to the date of an event. Patients lost to follow-up were censored on the latest follow-up date. Multivariate analysis was performed using the Cox proportional hazards model. Kaplan-Meier analysis and log-rank tests were also performed to compare prognostic differences between two groups. For all analyses, a $P$-value $<0.05$ was considered statistically significant.

\section{Results}

As shown in Table 2, 124 cases of NPC comprised 5 keratinizing squamous cell carcinomas, 42 non-keratinizing differentiated carcinomas, and 77 non-keratinizing, undifferentiated carcinomas. A total of 95 males and 29 females with a mean age of 48.6 years (range, 20-83) were included in the present study. Seven cases were classified as stage I; 31 cases were classified as stage II; 46 cases were classified as stage III; and 40 cases were classified as stage IV. All 124 cases had been tested for EBV infection by in situ hybridization for the EBV-encoded mRNA (EBER-ISH) as stated in our previous same cohort [17]. All but one had EBER expression. The only one EBER-negative case was classified as keratinizing squamous cell carcinoma.
Table 2. Associations between $\mathrm{HOXC6}$ and $\mathrm{Ki}-67$ expressions with other important clinicopathologic variables.

\begin{tabular}{|c|c|c|c|c|c|c|c|}
\hline \multirow[t]{2}{*}{ Parameters } & \multirow[t]{2}{*}{ Category } & \multicolumn{2}{|c|}{ HOXC6 Exp. } & \multirow[t]{2}{*}{ p-value } & \multicolumn{2}{|l|}{ Ki-67 } & \multirow[t]{2}{*}{ p-value } \\
\hline & & Low & High & & Low & High & \\
\hline \multirow[t]{2}{*}{ Gender } & Male & 46 & 49 & 0.524 & 50 & 45 & 0.289 \\
\hline & Female & 16 & 13 & & 12 & 17 & \\
\hline \multirow[t]{2}{*}{ Age (years) } & $<60$ years & 46 & 52 & 0.186 & 49 & 49 & 1.000 \\
\hline & $>=60$ years & 16 & 10 & & 13 & 13 & \\
\hline \multirow{2}{*}{$\begin{array}{l}\text { Primary } \\
\text { tumor }(\mathrm{T})\end{array}$} & T1-T2 & 46 & 34 & $0.024^{*}$ & 43 & 37 & 0.260 \\
\hline & T3-T4 & 16 & 28 & & 19 & 25 & \\
\hline \multirow{2}{*}{$\begin{array}{l}\text { Nodal status } \\
\text { (N) }\end{array}$} & N0-N1 & 38 & 18 & $<0.001^{*}$ & 26 & 30 & 0.470 \\
\hline & N2-N3 & 24 & 44 & & 36 & 32 & \\
\hline \multirow[t]{2}{*}{ Stage } & I-II & 27 & 11 & $0.002^{*}$ & 19 & 19 & 1.000 \\
\hline & III-IV & 35 & 51 & & 43 & 43 & \\
\hline \multirow{3}{*}{$\begin{array}{l}\text { Histological } \\
\text { grade }\end{array}$} & Keratinizing & 2 & 3 & 0.814 & 3 & 2 & 0.163 \\
\hline & Non-keratinizing & 20 & 22 & & 16 & 26 & \\
\hline & Undifferentiated & 40 & 37 & & 43 & 34 & \\
\hline \multirow[t]{2}{*}{ Ki-67 } & Low Exp. & 41 & 21 & $<0.001^{*}$ & - & - & - \\
\hline & High Exp. & 21 & 41 & & - & - & - \\
\hline
\end{tabular}

*, Statistically significant

Normal nasopharyngeal mucosa presented either negative or very low HOXC6 staining (Fig. 2A), whereas NPC cases showed nuclear staining of HOXC6 (Fig. 2B). The H scores of 62 cases were less than the median value and therefore classified as low HOXC6 expression (Fig. 2D); another 62 cases showed high HOXC6 expression (H score > median; Fig. 2C). Accordingly, there are 62 cases classified as high Ki-67 expression (Fig 2E), and another 62 cases classified as low Ki-67 expression (Fig 2F).

We found that HOXC6 overexpression was significantly and positively correlated with Ki-67 expression $(p<0.001)$, and they are significantly associated with advanced tumor stage $(p=0.024)$, advanced nodal status $(\mathrm{p}<0.001)$ and AJCC stage $(\mathrm{p}=0.002)$ (Table 2). HOXC6 high expression was also univariately correlated with a worse prognosis in terms of DSS $(p=0.008)$ and MeFS $(p=0.0047)$ (Table 3$)$. HOXC6 overexpression remained as an independent predictor in multivariate models (Table 4), and portended worse DSS $(\mathrm{p}=0.015$, hazard ratio $=1.988)$ and MeFS $(p=0.036$, hazard ratio $=1.899)$, together with advanced AJCC stages III-IV ( $p=0.024$, DSS; $p=0.043$, MeFS).

\section{Discussion}

Herein, we presented the first demonstration of HOXC6 expression in a large cohort of NPC patients and characterized its association with Ki-67 proliferation index, as well as prognostic parameters and survival outcome. The HOXC6 gene, which is silent in normal nasopharyngeal mucosal tissue, is upregulated in 62 cases in the NPC cohort examined in the present study, and the expression of this gene also appears to be a potent prognosticator for DSS and 
DMeFS and is significantly associated with high Ki-67 labeling index, implying the potential role of this gene in tumor proliferation and/or progression. These findings suggest that disturbances in the normal pattern of HOX gene expression are associated with NPC tumorigenesis and progression. Despite positive correlations between HOXC6 expression and Ki-67 proliferation index, there was no significant association between Ki-67 expression and T-stages of tumor or lymph node metastasis, probably indicating cell proliferation is an inherent characteristic of NPC and is not related to the size of the primary tumor and lymph node metastasis.

Table 3. Univariate log-rank analyses.

\begin{tabular}{|c|c|c|c|c|c|c|c|c|}
\hline \multirow[t]{2}{*}{ Parameters } & \multirow[t]{2}{*}{ Category } & \multirow{2}{*}{$\begin{array}{l}\text { No. of } \\
\text { case }\end{array}$} & \multicolumn{2}{|l|}{ DSS } & \multicolumn{2}{|l|}{ MeFS } & \multicolumn{2}{|l|}{ LRFS } \\
\hline & & & No. of event & p-value & No. of event & p-value & No. of event & p-value \\
\hline \multirow[t]{2}{*}{ Gender } & Male & 95 & 45 & 0.7870 & 38 & 0.6128 & 30 & 0.3240 \\
\hline & Female & 29 & 14 & & 11 & & 7 & \\
\hline \multirow[t]{2}{*}{ Age (years) } & $<60$ years & 98 & 48 & 0.8600 & 42 & 0.3091 & 29 & 0.8206 \\
\hline & $>=60$ years & 26 & 11 & & 7 & & 8 & \\
\hline \multirow[t]{2}{*}{ Primary tumor $(\mathrm{T})$} & T1-T2 & 80 & 32 & $0.0289^{*}$ & 25 & $0.0085^{*}$ & 19 & $0.0180^{*}$ \\
\hline & T3-T4 & 44 & 27 & & 24 & & 18 & \\
\hline \multirow[t]{2}{*}{ Nodal status (N) } & N0-N1 & 56 & 18 & $0.0008^{*}$ & 17 & $0.0132^{*}$ & 12 & $0.0160^{*}$ \\
\hline & N2-N3 & 68 & 41 & & 32 & & 25 & \\
\hline \multirow[t]{2}{*}{ Stage } & I-II & 38 & 10 & $0.0020^{*}$ & 9 & $0.0072^{*}$ & 5 & $0.0026^{*}$ \\
\hline & III-IV & 86 & 49 & & 40 & & 32 & \\
\hline \multirow[t]{2}{*}{ Histological grade } & Keratinizing/Non-keratinizing & 47 & 20 & 0.1980 & 17 & 0.2753 & 15 & 0.9521 \\
\hline & Undifferentiated & 77 & 39 & & 32 & & 22 & \\
\hline \multirow[t]{2}{*}{ HOXC6 } & Low Exp. (H-score<median) & 62 & 21 & $0.0008^{*}$ & 18 & $0.0047^{*}$ & 17 & 0.1887 \\
\hline & High Exp. (H-score>=median) & 62 & 38 & & 31 & & 20 & \\
\hline \multirow[t]{2}{*}{ Ki-67 } & Low Exp. (H-score<median) & 62 & 23 & 0.0863 & 19 & 0.1022 & 1126 & $0.0087^{*}$ \\
\hline & High Exp. (H-score>=median) & 62 & 36 & & 30 & & & \\
\hline
\end{tabular}

*, Statistically significant; DSS, disease-specific survival; MeFS, distal metastasis-free Survival; LRFS, local recurrence-free survival

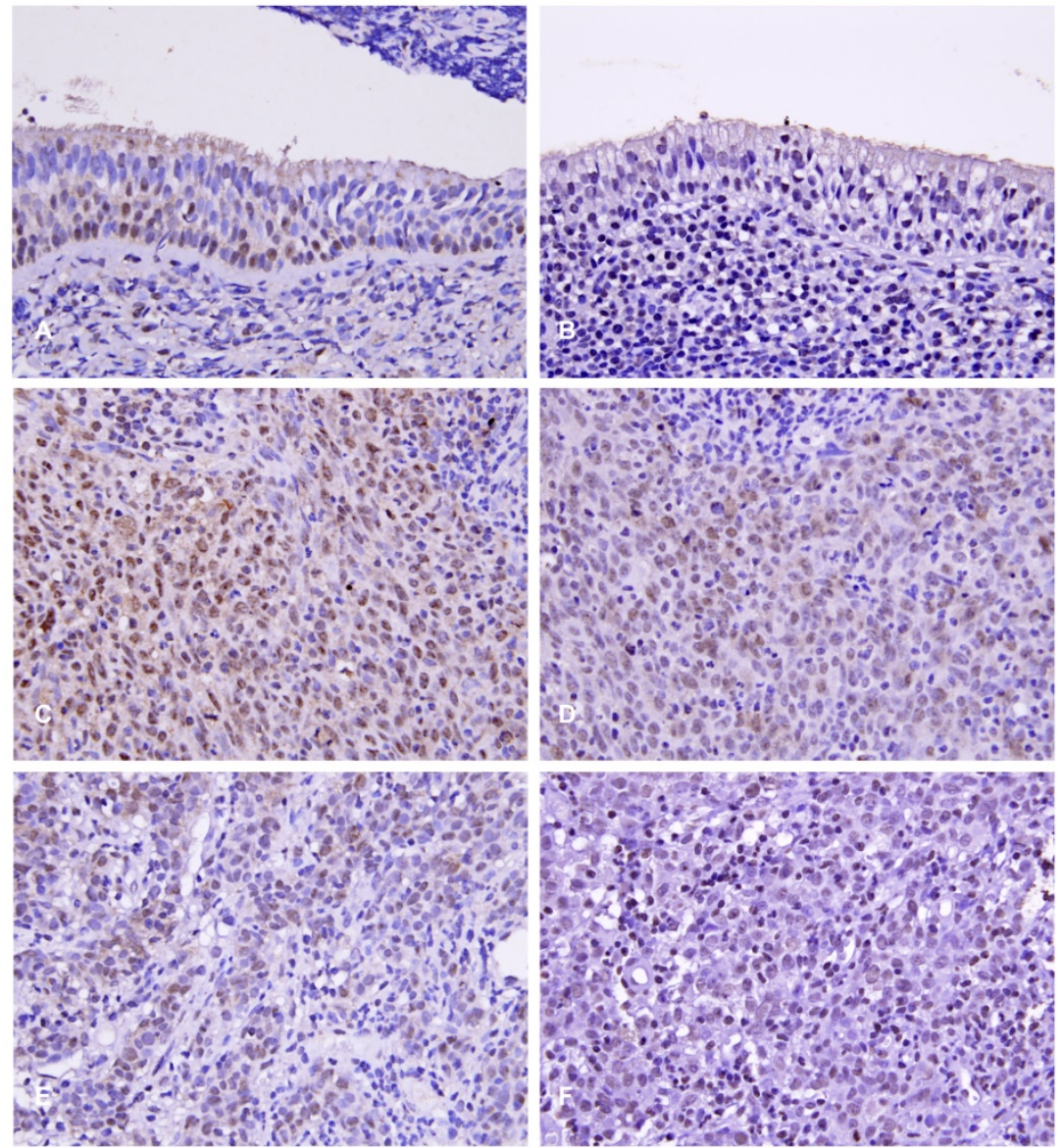

Figure 2. Immunoexpressions of HOXC6 and Ki-67 in normal nasopharyngeal tissue (A,B); a high-stage, nasopharyngeal carcinoma (C,D), and a low-stage nasopharyngeal carcinoma $(E, F)$, respectively. 

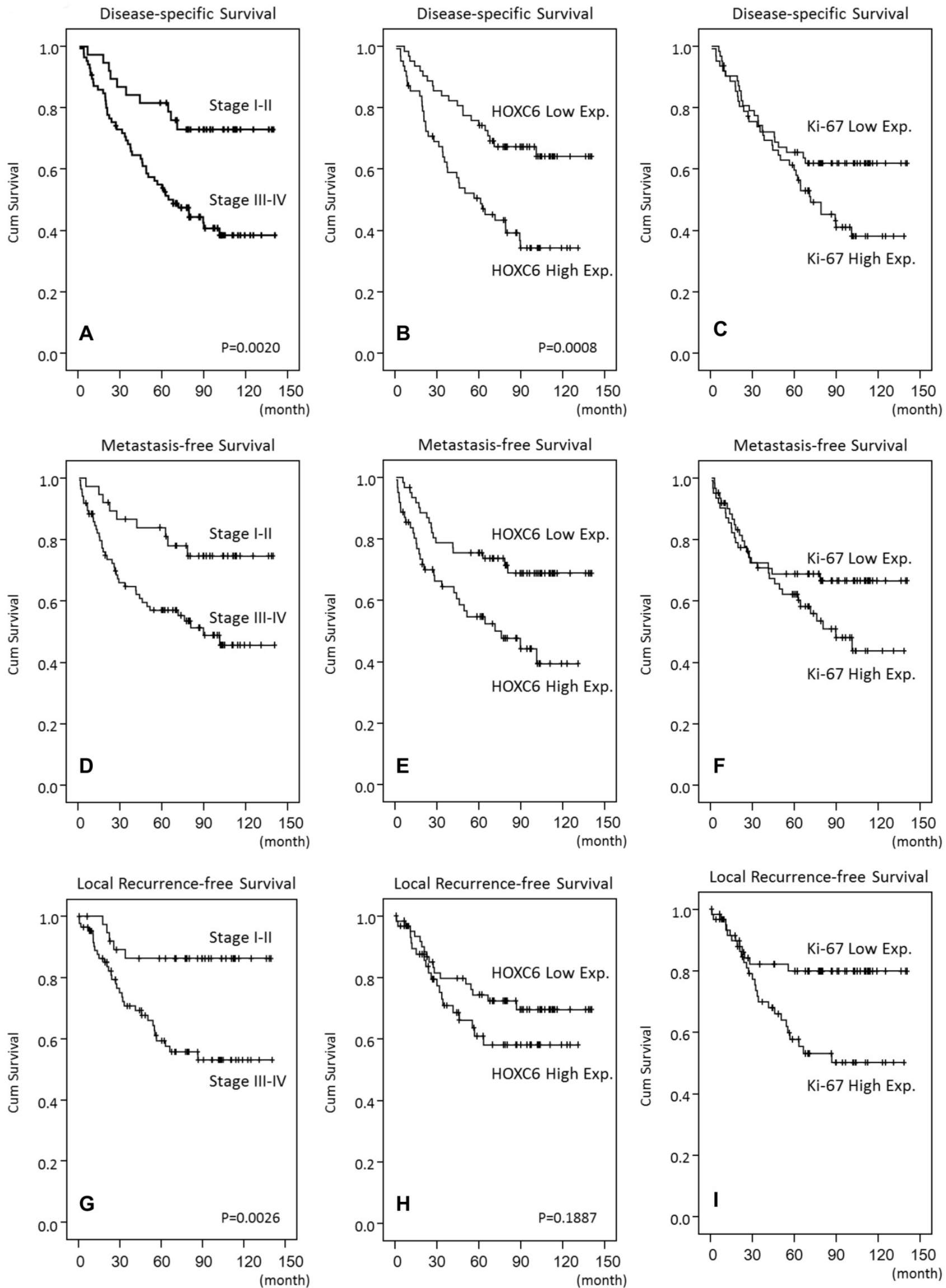

Figure 3. High $\mathrm{HOXC6}$ and $\mathrm{Ki}-67$ expression predicts inferior outcome in NPC patients. Disease-specific (B, C), distal metastasis-free (E, F), and local recurrence-free survivals $(\mathrm{H}, \mathrm{I})$ were plotted using Kaplan-Meier method. 
Table 4. Multivariate survival analyses

\begin{tabular}{|c|c|c|c|c|c|c|c|c|c|c|}
\hline \multirow[t]{2}{*}{ Parameter } & \multirow[t]{2}{*}{ Category } & \multicolumn{3}{|l|}{ DSS } & \multicolumn{3}{|l|}{ MeFS } & \multicolumn{3}{|l|}{ LRFS } \\
\hline & & H.R & $95 \%$ CI & $\mathrm{p}$-value & H.R & $95 \% \mathrm{CI}$ & p-value & H.R & $95 \% \mathrm{CI}$ & $\mathrm{p}$-value \\
\hline \multirow[t]{2}{*}{ Stage } & I-II & 1 & - & $0.024^{*}$ & 1 & - & $0.043^{*}$ & 1 & - & $0.012^{*}$ \\
\hline & III-IV & 2.253 & $1.115-4.550$ & & 2.161 & $1.026-4.553$ & & 2.532 & $1.226-5.230$ & \\
\hline \multirow[t]{2}{*}{ HOXC6 Exp. } & Low. Exp. & 1 & - & $0.015^{*}$ & 1 & - & $0.036^{*}$ & - & - & - \\
\hline & High Exp. & 1.988 & $1.146-3.451$ & & 1.899 & $1.044-3.457$ & & - & - & - \\
\hline \multirow[t]{2}{*}{ Ki-67 Exp. } & Low Exp. & - & - & - & - & - & - & 1 & - & 0.145 \\
\hline & High Exp. & - & - & - & - & - & - & 1.534 & $0.862-2.729$ & \\
\hline
\end{tabular}

*, Statistically significant

Cancer progression and normal development are similar, as both processes involve shifts between cell proliferation and differentiation. Recent studies have demonstrated that the improper regulation of development genes may result in cancer [18]. However, there is much to learn about the interplay between development, cell cycle, apoptosis and cancer. Cellular transformation involves the expression of intact or altered proteins coordinately regulated by multiple transcription factors, including homeodomain-containing proteins. In addition to their role in embryogenesis, HOX genes are expressed in adult cells, where these genes regulate the expression of genes involved in cell proliferation and cell-cell and cell-extracellular matrix interactions. The specific mechanisms by which HOX genes contribute to the tumorigenic phenotype have not been fully described.

Initial observations of HOX gene involvement in breast cancer have highlighted a role for the genes from loci A and C of the HOX network [19]. HOXC6 expression in breast carcinomas contributes to the breast cell phenotype through interactions with other HOX genes (HOXB7) or through the repression of target genes [20]. In addition, the expression of the entire HOX gene network in pairs of normal-tumorous bladder samples and isolated tumor biopsies was recently described. Cantile $\mathrm{M}$ et al. observed that the HOXC6 gene is silent in the normal bladder but active in $100 \%$ of the examined 30 cases of TCC [21]. Previous studies have shown the up-regulation of genes from the HOXC locus (HOXC4, HOXC5, HOXC6 and HOXC8) in malignant prostate cell lines and lymph node metastases [10,11]. These observations demonstrate that HOXC6 is a crucial gene that predicts the clinical outcome of prostate cancers. Moreover, these findings suggest that crucial unknown cancer genes can be identified via the study of the HOX gene network during tumor progression. This accumulating evidence indicates that the expression patterns of HOX genes are different between cancer and normal tissues in different types of human solid cancers, including renal, prostate, and bladder. These observations highlight the importance of the HOX network in cancer evolution and suggest the possibility to target
HOX genes for future cancer therapies.

In a study by Moon SM et al., HOXC6 and Bcl-2 genes were identified as being overexpressed in head and neck squamous cell carcinoma tissue and cell lines, and transfection assays showed that HOXC6 increased the levels of Bcl-2 mRNA and protein. The study presented that HOXC6 regulated cellular anti-apoptotic pathway and enhanced cell proliferative activity by directly binding to the bcl-2 promoter region [22]. Quantification of cell proliferative activity in neoplasia is currently a subject of considerable investigation. Ki-67 is a nuclear antigen expressed at the highest concentration in all stages of the cell cycle but not in resting cells. MIB-1 is a monoclonal antibody that recognizes a fixation resistant epitope of the $\mathrm{Ki}-67$ antigen and is used to estimate the proliferative fraction of neoplasia. Our findings of the positive correlation of high expression of HOXC6 to high Ki-67 labeling index in NPC further support the role of HOXC6 in regulation of tumor proliferation.

Recently, chemotherapy has been used as induction therapy for patients with NPC concurrently with radiotherapy for locally advanced disease, and as a major therapy for those with metastatic disease $[23,24]$. However, the outcome of patients with recurrent or metastatic NPC remains unsatisfactory. The drug resistance phenomenon may be one of the contributing causes. MDR-1, a 170-kd membrane protein, is a multidrug efflux pump conferring drug resistance to healthy cells or tumor cells exposed to chemotherapeutic drugs, such as vinca alkaloids, taxanes, actinomycin D, doxorubicine, and etoposide (VP-16) [25, 26]. CL Chen et al. [27] detected MDR-1 in tumor cells in $12.6 \%$ of patients with primary NPC and in $32.6 \%$ of patients with recurrent NPC $(p=0024)$. It is interesting that the study of K-J Kim et al. showed the evidence of overexpression of HOXC6 induced upregulation of MDR-1 mRNA levels and increased drug resistance [28]. These findings suggest an important mechanism of HOXC6 in chemotherapeutic drug resistance via its regulation of MDR-1 in a subset of NPC patients.

To our knowledge, this is the first study to analyze the correlations between HOXC6 immunoexpression and survival outcomes of NPC 
patients. The results of this retrospective study showed that HOXC6 was an independent prognostic parameter for patients with NPC. Our findings stress the importance of the HOX network in carcinogenesis and highlight the possibility to identify crucial unknown cancer genes through the study of the HOX gene network. As the precise molecular mechanism of the development and progression of NPC remains poorly understood, in-depth understanding of the molecular alterations in and across the cellular pathways involved in NPC carcinogenesis will certainly facilitate the integration of diagnosis, anticancer drug discovery, and therapy for NPC.

\section{Competing Interests}

The authors have declared that no competing interest exists.

\section{References}

1. Yu MC, Yuan JM. Epidemiology of nasopharyngeal carcinoma. Seminars in cancer biology. 2002; 12: 421-9.

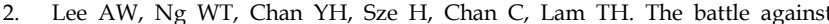
nasopharyngeal cancer. Radiotherapy and oncology : journal of the European Society for Therapeutic Radiology and Oncology. 2012; 104: 272-8.

3. Scott MP, Tamkun JW, Hartzell GW, 3rd. The structure and function of the homeodomain. Biochimica et biophysica acta. 1989; 989: 25-48.

4. Duboule D, Boncinelli E, DeRobertis E, Featherstone M, Lonai P, Oliver G, et al. An update of mouse and human HOX gene nomenclature. Genomics. 1990; 7: 458-9.

5. McAlpine PJ, Shows TB. Nomenclature for human homeobox genes. Genomics. 1990; 7: 460 .

6. Acampora D, D'Esposito M, Faiella A, Pannese M, Migliaccio E, Morelli F, et al. The human HOX gene family. Nucleic acids research. 1989; 17: 10385-402.

7. Cillo C, Cantile M, Faiella A, Boncinelli E. Homeobox genes in normal and malignant cells. Journal of cellular physiology. 2001; 188: 161-9.

8. Owens BM, Hawley RG. HOX and non-HOX homeobox genes in leukemic hematopoiesis. Stem cells. 2002; 20: 364-79.

9. Care A, Silvani A, Meccia E, Mattia G, Stoppacciaro A, Parmiani G, et al. HOXB7 constitutively activates basic fibroblast growth factor in melanomas. Molecular and cellular biology. 1996; 16: 4842-51.

10. Miller GJ, Miller HL, van Bokhoven A, Lambert JR, Werahera PN, Schirripa O, et al. Aberrant HOXC expression accompanies the malignant phenotype in human prostate. Cancer research. 2003; 63: 5879-88

11. Ramachandran S, Liu P, Young AN, Yin-Goen Q, Lim SD, Laycock N, et al. Loss of HOXC6 expression induces apoptosis in prostate cancer cells. Oncogene. 2005; 24: 188-98

12. Bridger JM, Kill IR, Lichter P. Association of pKi-67 with satellite DNA of the human genome in early G1 cells. Chromosome research : an international journal on the molecular, supramolecular and evolutionary aspects of chromosome biology. 1998; 6: 13-24.

13. Kao YC, Lee SW, Lin LC, Chen LT, Hsing CH, Hsu HP, et al. Fatty acid synthase overexpression confers an independent prognosticator and associates with radiation resistance in nasopharyngeal carcinoma. Tumour biology : the journal of the International Society for Oncodevelopmental Biology and Medicine. 2013; 34: 759-68.

14. Win KT, Lee SW, Huang HY, Lin LC, Lin CY, Hsing CH, et al. Nicotinamide $\mathrm{N}$-methyltransferase overexpression is associated with Akt phosphorylation and indicates worse prognosis in patients with nasopharyngeal carcinoma. Tumour biology : the journal of the International Society for Oncodevelopmental Biology and Medicine. 2013; 34: 3923-31.

15. Hsu HP, Li CF, Lee SW, Wu WR, Chen TJ, Chang KY, et al. Overexpression of stathmin 1 confers an independent prognostic indicator in nasopharyngeal carcinoma. Tumour biology : the journal of the International Society for Oncodevelopmental Biology and Medicine. 2014; 35: 2619-29.

16. Wolden SL, Zelefsky MJ, Kraus DH, Rosenzweig KE, Chong LM, Shaha AR, et al. Accelerated concomitant boost radiotherapy and chemotherapy for advanced nasopharyngeal carcinoma. Journal of clinical oncology : official journal of the American Society of Clinical Oncology. 2001; 19: 1105-10.

17. Lee YE, He HL, Chen TJ, Lee SW, Chang IW, Hsing CH, et al. The prognostic impact of RAP2A expression in patients with early and locoregionally advanced nasopharyngeal carcinoma in an endemic area. American journal of translational research. 2015; 7: 912-21.

18. Abate-Shen C. Deregulated homeobox gene expression in cancer: cause or consequence? Nature reviews Cancer. 2002; 2: 777-85.
19. Friedmann $Y$, Daniel CA, Strickland P, Daniel CW. Hox genes in normal and neoplastic mouse mammary gland. Cancer research. 1994; 54: 5981-5.

20. Chariot A, Castronovo V, Le P, Gillet C, Sobel ME, Gielen J. Cloning and expression of a new HOXC6 transcript encoding a repressing protein. The Biochemical journal. 1996; 319 ( Pt 1): 91-7.

21. Cantile M, Cindolo L, Napodano G, Altieri V, Cillo C. Hyperexpression of locus $\mathrm{C}$ genes in the HOX network is strongly associated in vivo with human bladder transitional cell carcinomas. Oncogene. 2003; 22: 6462-8.

22. Moon SM, Kim SA, Yoon JH, Ahn SG. HOXC6 is deregulated in human head and neck squamous cell carcinoma and modulates Bcl-2 expression. The Journal of biological chemistry. 2012; 287: 35678-88.

23. Fu KK. Combined radiotherapy and chemotherapy for nasopharyngeal carcinoma. Seminars in radiation oncology. 1998; 8: 247-53.

24. Hong RL, Sheen TS, Ko JY, Hsu MM, Wang CC, Ting LL. Induction with mitomycin C, doxorubicin, cisplatin and maintenance with weekly 5-fluorouracil, leucovorin for treatment of metastatic nasopharyngeal carcinoma: a phase II study. British journal of cancer. 1999; 80: 1962-7.

25. Schinkel AH, Borst P. Multidrug resistance mediated by P-glycoproteins. Seminars in cancer biology. 1991; 2: 213-26.

26. Dietel M. What's new in cytostatic drug resistance and pathology. Pathology, research and practice. 1991; 187: 892-905.

27. Chen CL, Sheen TS, Lou IU, Huang AC. Expression of multidrug resistance 1 and glutathione-S-transferase-Pi protein in nasopharyngeal carcinoma. Human pathology. 2001; 32: 1240-4.

28. Kim KJ, Moon SM, Kim SA, Kang KW, Yoon JH, Ahn SG. Transcriptional regulation of MDR-1 by HOXC6 in multidrug-resistant cells. Oncogene. 2013; 32: $3339-49$ 